\title{
Calibration of Scatterometer Wind Speed under Hurricane Conditions
}

\author{
Agustinus Ribal, ${ }^{\mathrm{a}, \mathrm{b}}$ Ali TAmizi, ${ }^{\mathrm{a}}$ AND IAN R. YounG ${ }^{\mathrm{a}}$ \\ ${ }^{a}$ Department of Infrastructure Engineering, University of Melbourne, Parkville, Victoria, Australia \\ ${ }^{\mathrm{b}}$ Department of Mathematics, Faculty of Mathematics and Natural Sciences, Hasanuddin University, Makassar, Indonesia
}

(Manuscript received 25 April 2021, in final form 26 August 2021)

\begin{abstract}
Four scatterometers, namely, MetOp-A, MetOp-B, ERS-2, and OceanSat-2 were recalibrated against combined National Data Buoy Center (NDBC) data and aircraft Stepped Frequency Microwave Radiometer (SFMR) data from hurricanes. As a result, continuous calibration relations over the wind speed range from 0 to $45 \mathrm{~m} \mathrm{~s}^{-1}$ were developed. The calibration process uses matchup criteria of $50 \mathrm{~km}$ and $30 \mathrm{~min}$ for the buoy data. However, due to the strong spatiotemporal wind speed gradients in hurricanes, a method that considers both scatterometer and SFMR data in a stormcentered translating frame of reference is adopted. The results show that although the scatterometer radar cross section is degraded at high wind speeds, it is still possible to recover wind speed data using the recalibration process. Data validation between the scatterometers shows that the calibration relations produce consistent results across all scatterometers and reduce the bias and root-mean-square error compared to previous calibrations. In addition, the results extend the useful range of scatterometer measurements to as high as $45 \mathrm{~m} \mathrm{~s}^{-1}$.
\end{abstract}

KEYWORDS: Hurricanes/typhoons; Tropical cyclones; Wind

\section{Introduction}

Satellite-based platforms such as scatterometers, radiometers, and altimeters can all measure wind speed. Scatterometers can, in addition, also measure wind direction. Such platforms have now been in operation for more than 25 years and provide global coverage. Therefore, such systems have been applied to both operational and longer-term climatological applications. Calibration and cross validation are critical for such multiplatform systems (Ribal and Young 2020b; Young and Ribal 2019; Young et al. 2017, 2020). Although understanding mean global wind climate and potential changes in this climate is important, for many applications (e.g., engineering design, operational risk analysis) reliable measurements of extreme winds are critical. At high wind speeds (greater than $25 \mathrm{~m} \mathrm{~s}^{-1}$ ), however, scatterometers display a low bias due to reduced backscatter signal (Chou et al. 2013; Hersbach et al. 2007; Tamizi et al. 2020; Verhoef et al. 2012). This raises the question of whether scatterometers represent a useful observation system for such extreme winds and, if so, whether the reported bias can be addressed by recalibration.

Traditionally, scatterometers have been calibrated and validated against in situ buoys (Bentamy et al. 2008; Pensieri et al. 2010; Ribal and Young 2020b; Satheesan et al. 2007; Verspeek et al. 2008) and fixed platforms (Alsabah et al. 2018; Madsen and Long 2016; Ribal and Young 2020b). As "ground truth," both buoys and platforms have limitations, particularly at high wind speeds. Buoys are potentially impacted by sheltering caused by large waves and tilting of the buoy axis (Bender et al. 2010; Jensen et al. 2015; Large et al. 1995; Taylor and Yelland 2001; Zeng and Brown 1998). Platforms are also impacted by flow disturbance around the structure. In addition, there is a

Corresponding author: Ian R. Young, ian.young@unimelb. edu.au paucity of quality wind observations, concurrent with scatterometer overpasses for calibration studies under extreme winds.

Tropical cyclones (or hurricanes in North America) represent a potentially important application for scatterometer measurements, as such systems represent the major sources of extreme winds in tropical and subtropical regions. As a result of the regular penetration of North American hurricanes by aircraft, they also provide a potential source of data to investigate the performance of scatterometers at extreme wind speeds. The dataset of dropwindsonde (Chou et al. 2013) and Stepped Frequency Microwave Radiometer (SFMR) data provides the possibility of observing high wind speeds during extreme conditions with high resolution and accuracy (Uhlhorn and Black 2003; Uhlhorn et al. 2007). Chou et al. (2013) have calibrated the MetOp- $A$ scatterometer against such dropwindsonde observations.

In all satellite system calibrations (scatterometer, radiometer, altimeter) collocation criteria need to be set to define an allowable observation matchup (i.e., acceptable differences in space and time between the "ground truth" measurement and satellite observation). This is particularly the case in attempting to calibrate scatterometer observations against hurricanebased SFMR or dropwindsonde data. Both the aircraft-based observations and satellite scatterometer are translating in space, and the times of observations seldom coincide. In addition, the structure of the hurricane wind field means that there are strong gradients of wind speed (in both space and time). Hence, obtaining reliable matchups is challenging. However, hurricanes can be modeled using relatively simple vortex structures and such an understanding of the wind field can assist in determining appropriate matchup criteria.

This paper considers the recalibration of the scatterometer missions: $E R S-2$, MetOp-A, OceanSat-2, and MetOp-B against a combination of SFMR data from North American hurricanes and buoy data. The SFMR data are used for wind speeds above approximately $15 \mathrm{~m} \mathrm{~s}^{-1}$ and buoy data for lower wind speeds. 
Parametric models of the hurricane wind field are utilized to reduce errors due to spatial and temporal mismatches between SFMR and scatterometer data. For each of the scatterometers, polynomial relationships are developed to provide calibration over the range from 0 to $45 \mathrm{~m} \mathrm{~s}^{-1}$.

Following this introduction, section 2 presents a description of the hurricane wind field and parametric models for the wind field. The data sources (hurricane position and wind field parameters, buoys, SFMR, scatterometer) used in the calibration procedures are described in section 3 and the calibration process in section 4 . The calibrated scatterometers are then validated against each other at global matchup locations (i.e., independent of hurricane observations). Finally, conclusions and discussion are included in section 6 .

\section{The hurricane wind field}

The 10 -m-elevation wind speed $\left(U_{10}\right)$ within a hurricane is often approximated by relatively simple parametric vortex models (Holland 1980; Holland et al. 2010; Willoughby et al. 2006). Holland et al. (2010) have described the hurricane wind field in terms of a small numbers of parameters typically available in hurricane track datasets. These parameters include the hurricane central pressure drop $(\Delta p)$, the velocity of forward movement $\left(V_{\mathrm{fm}}\right)$, radius of the maximum wind $\left(R_{m}\right)$, and a second radius of measured wind speed $\left(r_{n}\right)$. The surface wind speed at radius $r$ can be determined by

$$
U_{10}=\left[\frac{100 b_{s} \Delta p\left(\frac{R_{m}}{r}\right)^{b_{s}}}{\rho_{s} e^{\left(R_{m} / r\right)^{b_{s}}}}\right]^{x},
$$

where the subscript $s$ represents surface (10-m elevation) values. The quantity $\rho_{s}$ is the air density in $\mathrm{kg} \mathrm{m}^{-3}$ and $\Delta p$ is in $\mathrm{hPa}$. Following Holland et al. (2010), $b_{s}$ can be approximated by

$$
\begin{aligned}
b_{s}= & -4.4 \times 10^{-5}(\Delta p)^{2}+0.01(\Delta p)+0.03 \frac{\partial p}{\partial t} \\
& -0.014 \varphi+0.15 v_{\mathrm{fm}}^{q}+1.0, \\
q= & 0.6\left(1-\frac{\Delta p}{215}\right) .
\end{aligned}
$$

In (2), $\varphi$ is the absolute value of the latitude in degrees. The exponent $x$ in (1) is defined as

$$
\left\{\begin{array}{cl}
x=0.5 & r \leq R_{m} \\
x=0.5+\left(r-R_{m}\right) \frac{x_{n}-0.5}{r_{n}-R_{m}} & r>R_{m} .
\end{array} .\right.
$$

In (4), $x_{n}$ can be calculated from (2) if we know $U_{10}$ at radius $r_{n}$. Here we use $r_{n}=R_{34}$ (radius to gales), which is the radius at which the wind speed has a magnitude of $17.5 \mathrm{~m} \mathrm{~s}^{-1}$ (34 kt).

The Holland et al. (2010) model does not consider any asymmetry for the wind field. However, first-order asymmetry can be considered by the vector addition of the hurricane velocity of forward movement to the vectors of the surface wind field generated by the model (Hu et al. 2012; Xie et al. 2006; Young 2017). In addition, a constant inflow angle of $20^{\circ}$ has been assumed (Tamizi et al. 2020; Zhang and Uhlhorn 2012).

Tamizi et al. (2020) tested the performance of the Holland parametric model described above, with hurricane parameters from the International Best Track Archive for Climate Stewardship (IBTrACS) (Knapp et al. 2018). They compared the Holland wind field against $\mathrm{H}^{*}$ Wind gridded data for eight North Atlantic hurricanes and concluded that the model represents a reasonable approximation of hurricane wind fields, given the accuracy of the IBTrACS parameters. H*Wind (DiNapoli et al. 2012; Powell et al. 1998) is a software application used by NOAA's Hurricane Research Division to create a gridded tropical cyclone wind analysis based on a wide range of observations. These observations include aircraft data from SFMR and GPS dropwindsondes, satellite scatterometer observations, and in situ ship and buoy data.

To acquire hurricane data (wind speeds and wave heights) under a range of conditions and across the full spatial domain of the storm, a number of studies have pooled observations from multiple storms. To do this, these studies have typically adopted a frame of reference moving with the storm, with measurement locations being expressed relative to the position of the storm center and direction of translation (Collins et al. 2018; Klotz and Jiang 2016, 2017; Tamizi and Young 2020; Tamizi et al. 2020; Ueno and Bessho 2011; Uhlhorn et al. 2014; Young 1998; Young and Vinoth 2013; Young 2006). In the present study, the same process has been used for all hurricane data, and all observations have been transformed to a translating frame of reference with respect to the center of the storm. In this manner observations from different instruments can be related and collocated. All needed hurricane parameters and track information for transforming the observations have been estimated from IBTrACS data.

\section{Datasets}

The calibration/validation analysis requires a number of datasets to be utilized. These include scatterometer data, SFMR data from flights through hurricanes, NDBC buoy data from the North American region, and IBTrACS data of hurricane position and wind field parameters. Each of these datasets is briefly discussed below.

\section{a. Scatterometer data}

Ribal and Young (2020b) compiled a database of calibrated ocean wind speed measured by seven scatterometers: $E R S-1$, ERS-2, QuikSCAT, MetOp-A, OceanSat-2, MetOp-B, and RapidScat (expressed in the order of launch). The scatterometer data were calibrated, cross validated, and quality controlled. The duration of the combined dataset is approximately 27 years, from 1992 to 2018. However, since the database is updated every six months, the duration of the dataset at the time of writing was about 30 years, until March 2021. The data are archived on the Australian Ocean Data Network (AODN; portal.aodn.org.au) (Ribal and Young 2020b). The errors associated with (accuracy) these 


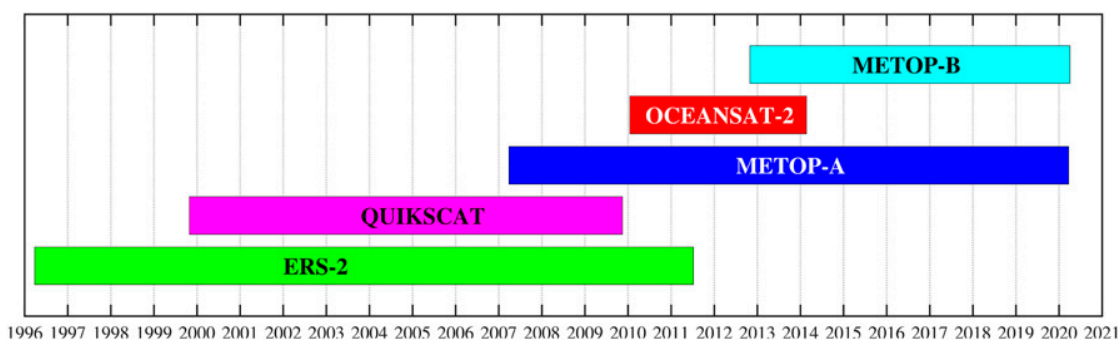

FIG. 1. Durations of scatterometer data used for the present work.

scatterometer data have been examined using triple collocation (Ribal and Young 2020a).

As noted by Tamizi et al. (2020), the IBTrACS dataset did not include all tropical cyclone wind field parameters during the period of operation of ERS-1 and the RapidScat mission was relatively short (2014-16). For these reasons, these scatterometers have not been recalibrated in this study. In addition, as shown by Tamizi et al. (2020), QuikSCAT appears to agree well with SFMR data up to $45 \mathrm{~ms}^{-1}$. Therefore, QuikSCAT was excluded from the recalibration and has been used in the present analysis as an independent dataset to validate the recalibrations of the other scatterometers. For this purpose, the QuikSCAT calibration proposed by Ribal and Young (2020b, their Table 2) has been used. As a result, four scatterometers have been recalibrated in this study: ERS-2, MetOp-A,OceanSat-2, and $M e t O p-B$. The durations of these scatterometer missions, as well as QuikSCAT are shown in Fig. 1. The wind speed and direction for MetOp-A and $M e t O p-B$ is available at $25 \mathrm{~km}$ resolution, while the resolution of $E R S$-2, QuikSCAT, and OceanSat-2 is $12.5 \mathrm{~km}$.

\section{b. Aircraft SFMR observations}

The Hurricane Research Division (HRD) of the National Oceanic and Atmospheric Administration (NOAA) gathers SFMR data of hurricanes from aircraft missions. Uhlhorn et al. (2007) have published observations of the hurricane surface wind from SFMR data. These data have high spatial resolution with respect to the size of the storm $(1.5 \mathrm{~km})$, and due to the mission flight paths, observations can be recorded from all four quadrants of the hurricane domain (Uhlhorn and Black 2003). Although such data are available only for North Atlantic hurricanes, it represents a valuable source of high wind speed observations for investigating extreme meteorological systems, as well as calibration and validation of models and observational instruments.

SFMR data are available for a number of hurricanes from 1998 to the present. As discussed in section 4a, below, all the observations are transformed to a translating tropical cyclone (TC) frame of reference, following Tamizi et al. (2020). For this process, hurricane wind field parameters, such as $R_{m}$, are required. Note that this parameter is generally not reported by IBTrACS before 2001, thus limiting the effective duration of SFMR observations to the period from 2001. The SFMR data were obtained from the NOAA HRD archive (https:// www.aoml.noaa.gov/hrd/data_sub/hurr.html) for 177 hurricanes from 2001 to 2017. Table 1 shows the statistics of the SFMR dataset that has been used in this study.

\section{c. NDBC buoy data}

As noted above, Ribal and Young (2020b) have previously calibrated wind speed measured for seven different scatterometers. To perform those calibrations, they considered National Data Buoy Center (NDBC) buoy data as "ground truth." Although limitations of the reliability of buoy data have been raised (Alves and Young 2003; Bender et al. 2010; Jensen et al. 2015; Large et al. 1995; Taylor and Yelland 2001; Vinoth and Young 2011; Zeng and Brown 1998), it is commonly used to validate model results and calibrate satellite observations. In particular, NDBC data are commonly used, as the dataset is both geographically and temporally extensive and regarded as high quality (Evans et al. 2003; Ribal and Young 2019; Zieger et al. 2015). In addition, Ribal and Young (2020b) also validated scatterometer data against platform measurements. Cross validations between scatterometers as well as between scatterometers and altimeters have also been carried out. These validations included examinations of stability and consistency of the measurements by evaluating wind speed differences between different satellites as a function of time.

For the present analysis, only buoys which are greater than $50 \mathrm{~km}$ offshore were used to avoid land or island contaminations. Figure 2 shows NDBC buoys which meet the criteria of being greater than $50 \mathrm{~km}$ offshore and were used in the analysis. The anemometers on these buoys measure wind speed $\left(U_{z}\right)$ at a variety of heights, where $z$ is the anemometer height. All data were transformed to a standard reference height of $10 \mathrm{~m}\left(U_{10}\right)$ using the assumption of a neutral-stability logarithm boundary layer. This approximation has been widely used in previous studies (Ribal and Young 2019, 2020a,b).

\section{Calibration against combined SFMR and NDBC buoy data}

\section{a. Data collocations}

To investigate scatterometer calibration at high wind speeds, matchups between scatterometer and hurricane SFMR data are required. For each hurricane with SFMR observations, the scatterometer database was searched for possible passes of the scatterometer within $10 R_{m}$ of the hurricane central position. That position was determined by linear interpolation between 
TABLE 1. Duration, number of hurricanes, and number of airplane mission for SFMR data.

\begin{tabular}{lccr}
\hline \hline Duration of SFMR database & No. of hurricanes & No. of airplane mission & No. of observations \\
\hline 23 Sep 2001-29 Oct 2017 & 177 & 1208 & 24566125 \\
\hline
\end{tabular}

specified locations within the IBTrACS database. These IBTrACS locations are generally provided at $6 \mathrm{~h}$ intervals (Tamizi et al. 2020). Previous satellite calibration studies (Ribal and Young 2020a,b; Young et al. 2017; Zieger et al. 2009) have typically defined allowable mismatches in space and time between the satellite and the "ground truth" (usually buoys). Values of $50 \mathrm{~km}$ and $30 \mathrm{~min}$ have commonly been used. The assumption in such an approach is that the wind speed will not vary greatly over the space-time mismatch. Although this may be true for most meteorological systems, the strong spatiotemporal gradients in hurricane wind fields, particularly near the storm center, means that unacceptably large errors can be introduced by such a matchup approach. Reducing the space and time mismatch leads to a significant reduction in the number of matchups and hence is not desirable.

However, it is possible to take advantage of the well-defined structure of the hurricane vortex, as defined by (1) to (4), and the fact that the parameters defining this vortex will not change significantly over the space and time mismatch. For all values which met the hurricane matchup criteria $(50 \mathrm{~km}$ and $120 \mathrm{~min}$, see below), the location of the hurricane was determined by linear interpolation within the IBTrACS data. The radius to maximum winds $R_{m}$, velocity of forward movement $V_{\mathrm{fm}}$, and the direction of propagation of the hurricane were assumed piecewise constant between IBTrACS data times. All observations (scatterometer and SFMR) were then placed in a frame of reference relative to the translating hurricane. An $0.5 R_{m} \times$ $0.5 R_{m}$ grid was placed over the hurricane region and referenced to the interpolated position of the hurricane center. All observations of scatterometer and SFMR wind speed were then allocated to the grid square in which they were located. The median values of wind speed within each grid square for each of scatterometer and SFMR were then determined over the 120-min mismatch period. These median values were then taken as the collocated observations for the calibration. A range of different time mismatch limits were tested, with minimal impact on the results for values up to $120 \mathrm{~min}$. As a result, the final matchup limits of $50 \mathrm{~km}$ and $120 \mathrm{~min}$ were used. The larger time mismatch is possible because we take advantage of the structure of the TC wind field in the matchup process.

Matchups were also required with buoy observations and the detailed procedures in obtaining the matchups between NDBC and scatterometer data have been reported in Ribal and Young (2020b), where space and time matchup criteria were $50 \mathrm{~km}$ and $30 \mathrm{~min}$, respectively. This means the scatterometer wind speed cell is within $50 \mathrm{~km}$ of the buoy location and the time difference between scatterometer and buoy is less than $30 \mathrm{~min}$. Moreover, if the number of scatterometer wind vector cells in the matchup period was less than five or the scatterometer data have large variability, then the wind speeds were excluded. The scatterometer data were categorized as having unacceptably large variability if $\sigma\left(U_{10}\right) / \bar{U}_{10}>0.2$, in which $\sigma\left(U_{10}\right)$ and $\bar{U}_{10}$ are the standard deviation and mean, respectively, of scatterometer wind speed vector cells, within a $50-\mathrm{km}$ radius around the buoy. It should be noted that these criteria were only applied for buoy data as the SFMR data use the storm-relative approach described above.

\section{b. Nonlinear calibration of scatterometer data}

Using the matchup criteria defined above, the data collocations were obtained between both scatterometers and NDBC buoy data and scatterometers and SFMR data. Before the $10 \mathrm{~m}$ elevation wind velocities for scatterometer and SFMR are compared, a correction needs to be applied to allow for the size of the scatterometer footprint $(25 \mathrm{~km} \times 25 \mathrm{~km}$

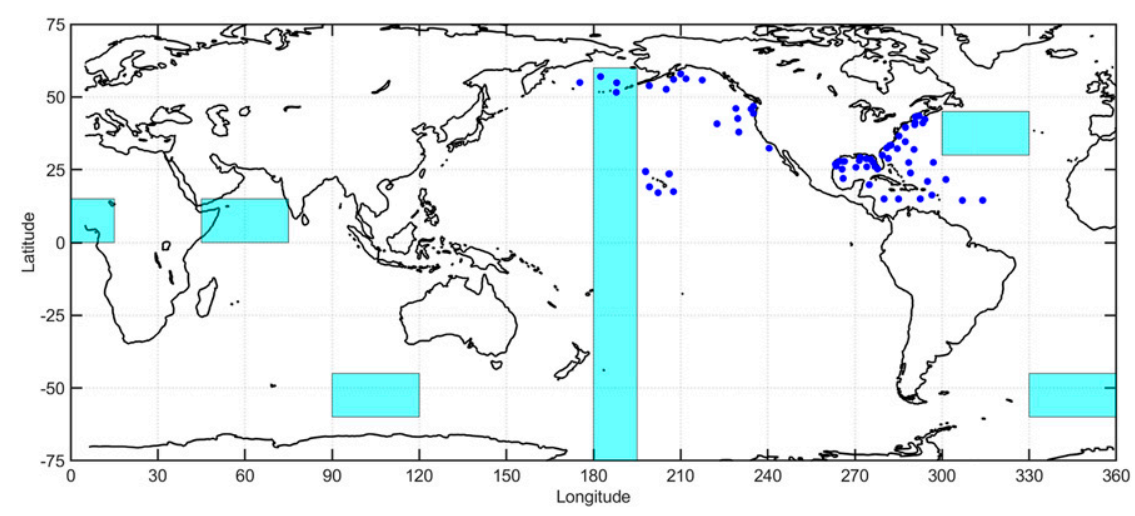

FIG. 2. NDBC buoy locations used in the present study. All buoys are greater than $50 \mathrm{~km}$ offshore. Cyan-shaded regions indicate the locations for MetOp-A and MetOp-B cross validations (see Ribal and Young 2020b). 

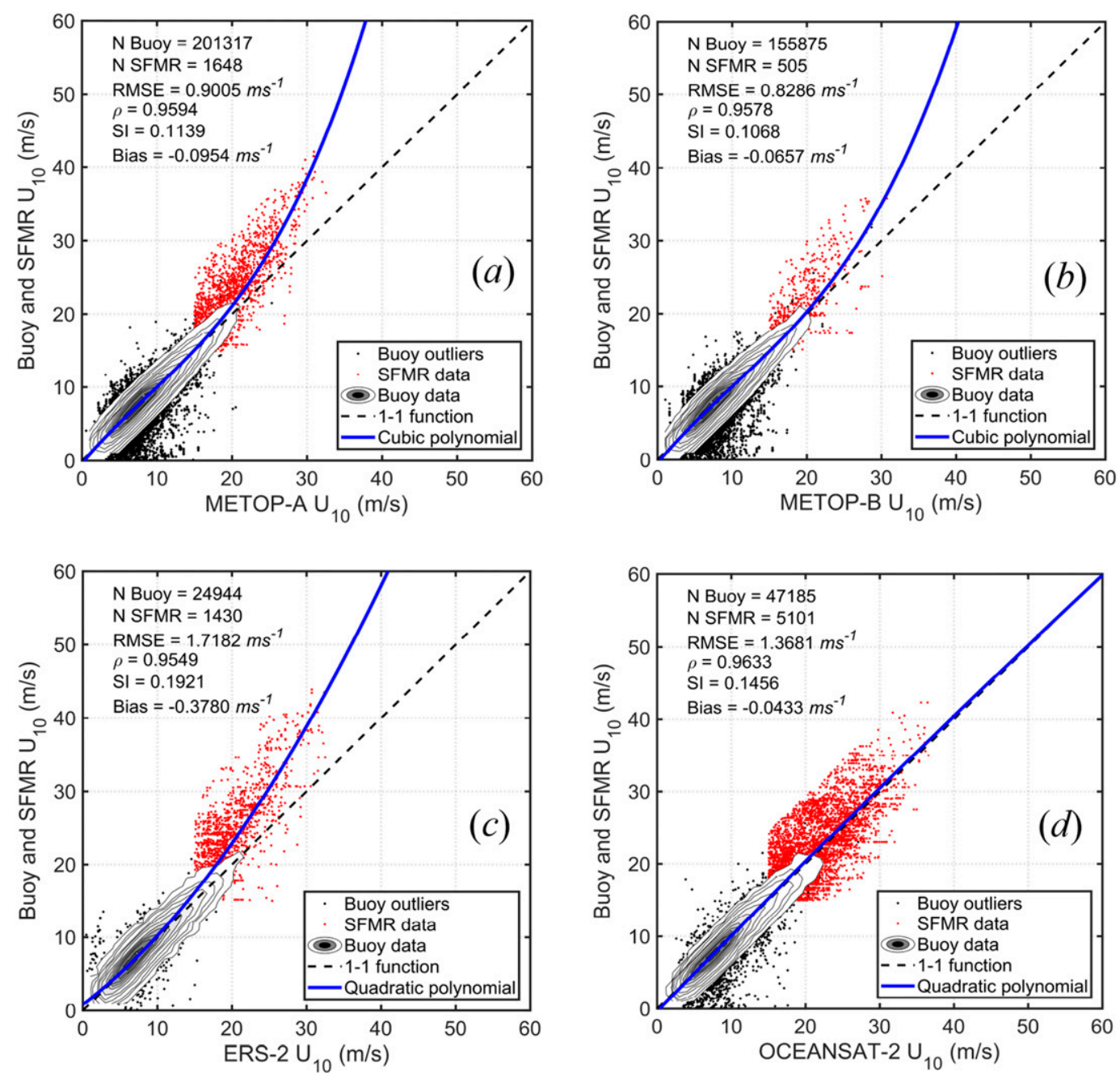

FIG. 3. Comparison of scatterometer wind speed against NDBC buoy and SFMR data. Dashed diagonal line and thick blue line represent the 1:1 reference line and the polynomial fit to the data from Table 1. Contours show the density of matchup data points between scatterometer and NDBC, which has been normalized such that the maximum value is 1.0. Contours are drawn at 0.9, 0.7, 0.5, 0.4, 0.3, 0.2, 0.1, and 0.05. (a) MetOp-A, (b) MetOp-B, (c) ERS-2, and (d) OceanSat-2.

or $12.5 \mathrm{~km} \times 12.5 \mathrm{~km})$. Because of the spatial gradients in the tropical cyclone wind field, the size of the scatterometer footprint acts as a spatial average and hence biases the scatterometer data low. Tamizi et al. (2020) used the Holland model [(1) to (4)] to estimate potential errors as a result of the relatively large scatterometer footprint $(12.5$ or $25 \mathrm{~km}$ depending on the scatterometer). They developed a correction factor, $S$, which is a function of the position of the scatterometer observation relative to the tropical cyclone center. The position is expressed in nondimensional coordinates, $x / R_{m}$ and $y / R_{m}$, where $x$ and $y$ are Cartesian locations relative to the center of the tropical cyclone. The correction factor $S$ is given by Tamizi et al. (2020, their Fig. 8) as a lookup table. This correction was applied to all scatterometer data in the form $U_{10}^{*}=U_{10} / S$, where $U_{10}^{*}$ is the corrected wind speed and $U_{10}$ is the uncalibrated wind speed reported by the scatterometer.
For the purposes of the calibration process, buoy and SFMR data were considered as "ground truth" even though these data do contain errors due to their sampling variability and instrument accuracy (Young et al. 2017; Zieger et al. 2009). Our aim is to develop calibration relations for the scatterometers over the full wind speed range from 0 to $45 \mathrm{~m} \mathrm{~s}^{-1}$. There are little SFMR data above this upper limit. To cover the full range, the buoy and SFMR data were combined. Although there are SFMR data over this full range, at lower wind speeds, the SFMR data were clearly more scattered than the buoy measurements. As a result, SFMR data were limited to $U_{10}>$ $15 \mathrm{~m} \mathrm{~s}^{-1}$. Figure 3 shows the values of scatterometer wind speed compared to the combined buoy and SFMR measurements at the respective matchup points. Note that footprintcorrected values of scatterometer wind speed $U_{10}^{*}$ are shown for SFMR matchups. Each of the panels in Fig. 3 report the 
TABLE 2. Nonlinear calibration relationships for scatterometer wind speed, where $U_{10}^{* *}$ and $U_{10}$ are the calibrated and uncalibrated data, respectively.

\begin{tabular}{ll}
\hline \hline Scatterometer & Relationship \\
\hline MetOp- $A$ & $U_{10}^{* *}=0.00093687 U_{10}^{3}-0.024773 U_{10}^{2}+1.1926 U_{10}-0.34796$ \\
MetOp- $B$ & $U_{10}^{* *}=0.00078545 U_{10}^{3}-0.024412 U_{10}^{2}+1.208 U_{10}-0.41381$ \\
ERS-2 & $U_{10}^{* *}=0.016373 U_{10}^{2}+0.77605 U_{10}+0.82952$ \\
OceanSat 2 & $U_{10}^{* *}=-0.00082251 U_{10}^{2}+1.0528 U_{10}-0.36009$ \\
\hline
\end{tabular}

number of both buoy and SFMR matchups used. The number of buoy matchups range between 24172 and 195825 whereas there are much less SFMR data with matchups ranging between 505 and 2923 values. As a result, the buoy data have been contoured in terms of the density of observations with "outliers" (see below) shown as separate points. Figure 3, clearly, shows that MetOp-A, MetOp-B, and ERS2 significantly underestimate at high wind speeds, while
OceanSat-2 slightly underestimates the high wind speed. This underestimation at high wind speed is consistent with the results of Chou et al. (2013) from dropwindsonde data for ASCAT $(\mathrm{Met} O p-A)$.

Data outliers were removed from the combined dataset prior to attempting to fit a calibration function to the combined dataset. The buoy and the SFMR outliers were removed using different approaches. Buoy outliers were removed using a
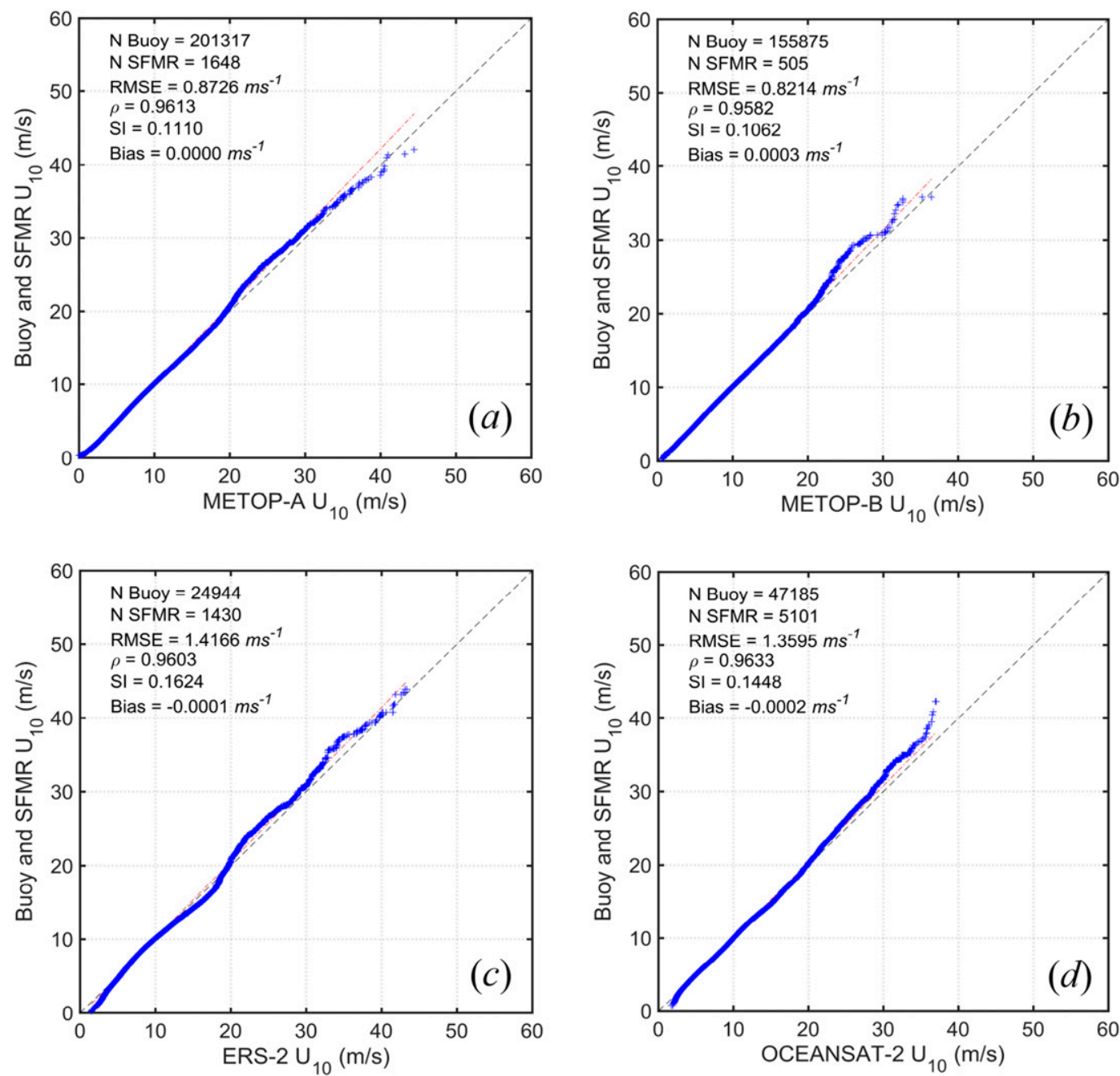

FIG. 4. Q-Q plots between the scatterometer and combined NDBC buoy and SFMR data for wind speed after the calibration was applied. (a) MetOp-A, (b) MetOp-B, (c) ERS-2, and (d) OceanSat-2. Dashed diagonal line represents the $1: 1$ reference line. 

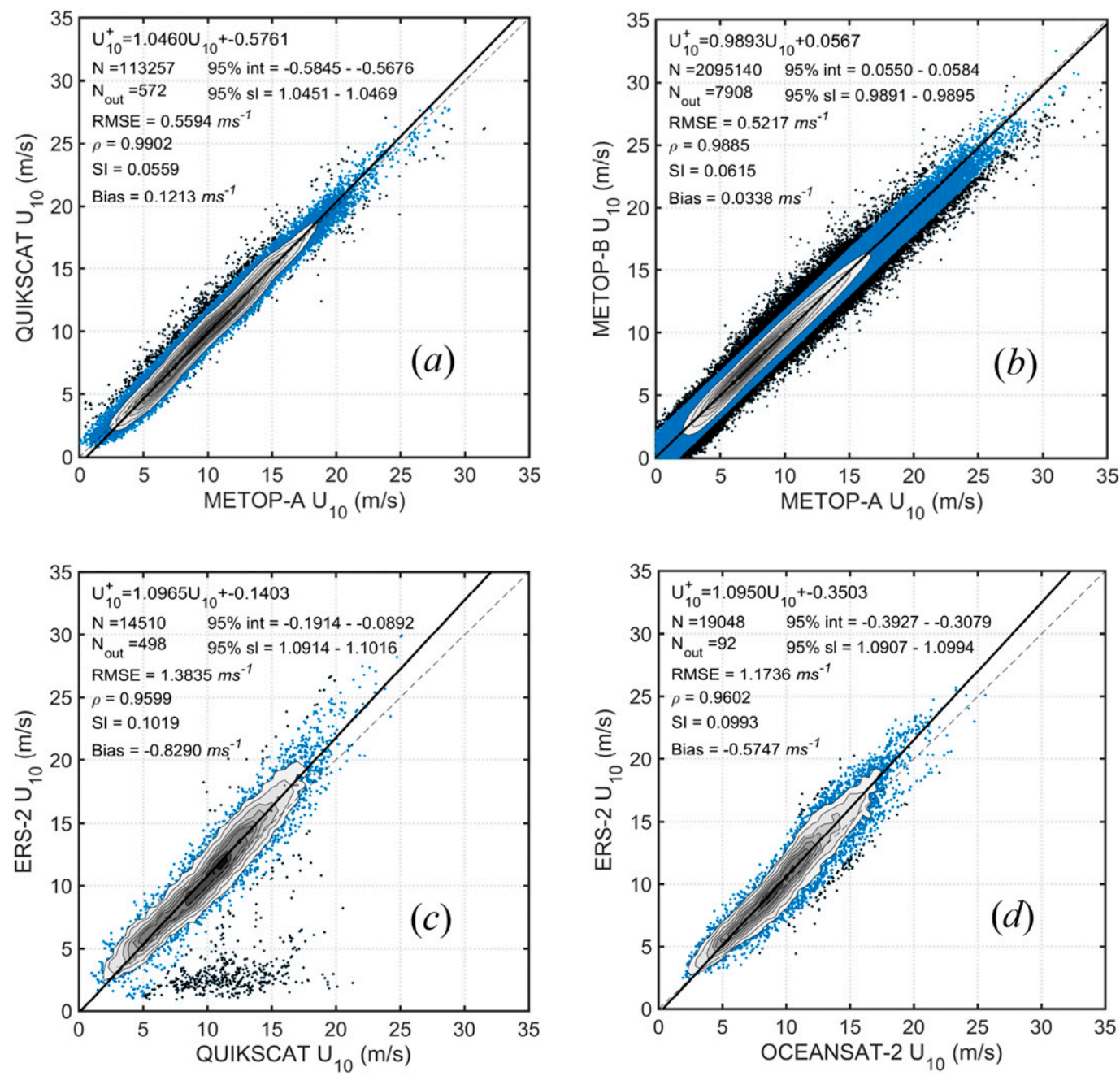

FIG. 5. Cross validation at matchup points between scatterometers. (a) $\mathrm{Met} O p$ - $A-Q u i k S C A T$, (b) $M e t O p-A-$ $M e t O p-B$, (c) QuikSCAT-ERS-2, (d) OceanSat-2-ERS-2. Dashed diagonal line and thick solid line represent the 1:1 relationship and the RMA regression, respectively. Contours show the density of matchup data points, which have been normalized such that the maximum value is 1.0 . Contours are drawn at $0.9,0.7,0.5,0.4,0.3,0.2$, 0.1 , and 0.05 . Black dots represent outliers excluded from the RMA regression while blue dots represent scatterplots of all data.

combination of robust regression and reduced major axis (RMA) regression (Holland and Welsch 1977). Robust regression assigns a weight to each point, with values between 0 and 1 . Points with a value less than 0.01 were designated as outliers. This approach was possible since there is an approximate linear relationship between the buoy and scatterometer wind speeds for the lower wind speeds for which these data were used. Since the relationship between SFMR data and scatterometer wind speed are mostly nonlinear, this procedure cannot be applied. For the SFMR data, the difference between SFMR and scatterometer wind speed were calculated. Then, the mean absolute deviation (MAD) for the difference can be calculated as (Huber 2005; Leys et al. 2013)

$$
\operatorname{MAD}=b \operatorname{median}\left\{\left|x_{i}-M_{n}\right|\right\},
$$

where $M_{n}=\operatorname{median}\left\{x_{i}\right\}$ and $x_{i}$ is the absolute difference between SFMR and scatterometer wind speed in which $i=1,2$, $3, \ldots, n$. The value of $n$ is the number of observations while the value of $b$ is given by 1.4826 which is the scaling factor for Gaussian distributions (Rousseeuw and Croux 1993). Furthermore, following Miller (1991), a threshold value of 3 has been chosen and hence all values which are outside the following criterion were categorized as outliers (Leys et al. 2013). The criterion is given by

$$
M_{n}-3 \times \mathrm{MAD}<x_{i}<M_{n}+3 \times \mathrm{MAD} .
$$

This equation can be rewritten as

$$
\left|\frac{x_{i}-M_{n}}{\operatorname{MAD}}\right|<3
$$



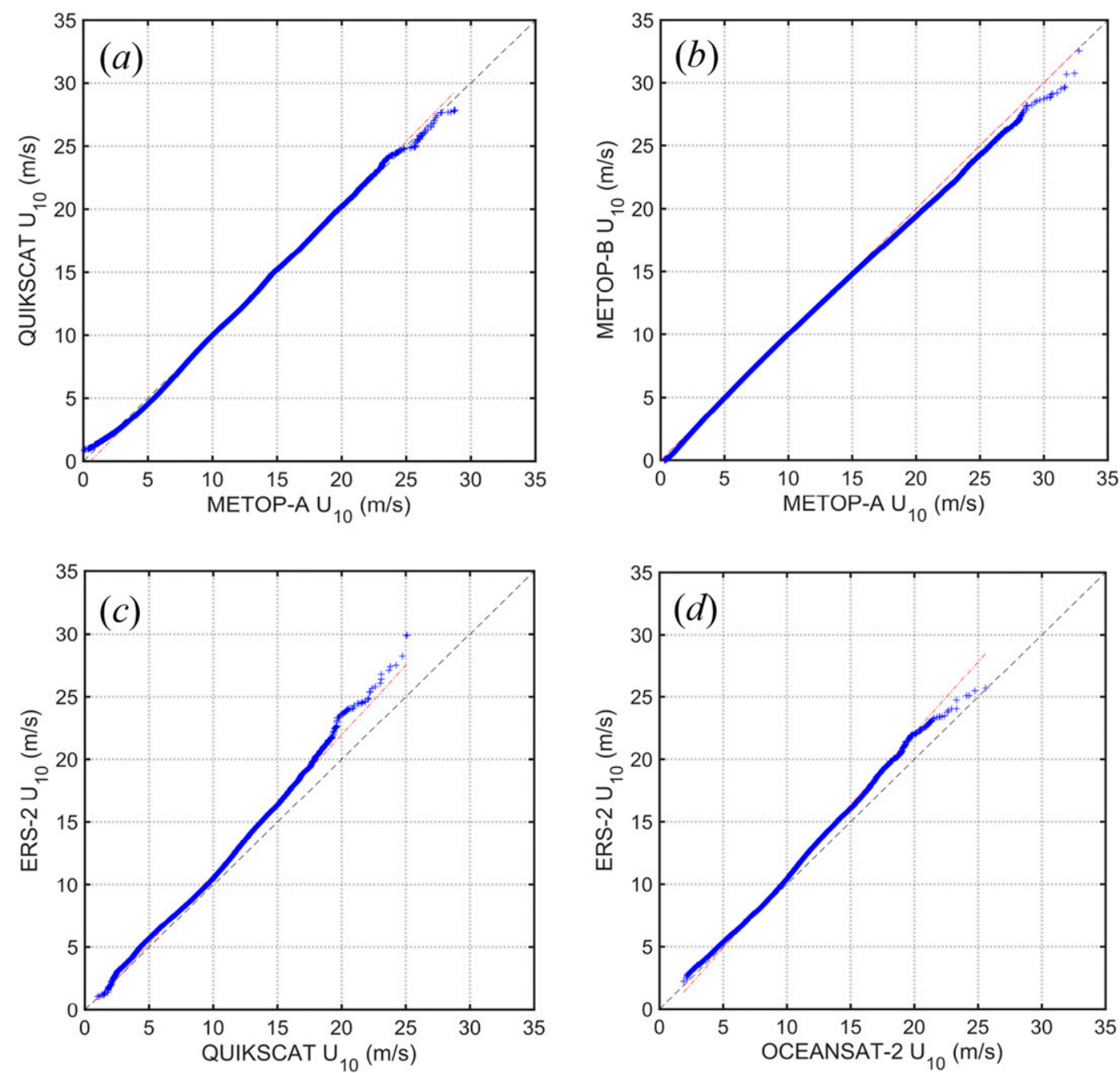

FIG. 6. Q-Q plots between the selected scatterometers. (a) $M e t O p-A-Q u i k S C A T$, (b) $M e t O p-A-M e t O p-B$, (c) QuikSCAT-ERS-2, and (d) OceanSat-2-ERS-2. Dashed diagonal line represents the 1:1 reference line.

Following the general approach of Chou et al. (2013), the data for each of the scatterometers in Fig. 3 were fitted using a least squares approach, with either second- or third-order polynomials. The best-fit relationships for each scatterometer are shown in Table 2. Figure 4 shows quantile-quantile (Q-Q) plots for each of the four scatterometers once the respective calibrations in Table 1 were applied. As can be seen in Fig. 4, the corrected scatterometer results now show good agreement with the recorded data over the full range of measured data $(0$ to approximately $45 \mathrm{~m} \mathrm{~s}^{-1}$ ).

To quantify the performance of the calibration, four different statistical parameters have been evaluated (Zieger et al. 2015):

$$
\begin{aligned}
B & =\frac{1}{N} \sum_{i=1}^{N}\left(M_{i}-O_{i}\right), \\
\mathrm{RMSE} & =\sqrt{\frac{1}{N} \sum_{i=1}^{N}\left(M_{i}-O_{i}\right)^{2},}
\end{aligned}
$$

$$
\begin{aligned}
& \mathrm{SI}=\frac{\sqrt{\frac{1}{N} \sum_{i=1}^{N}\left(M_{i}-O_{i}-B\right)^{2}}}{\frac{1}{N} \sum_{i=1}^{N} O_{i}}, \\
& \rho=\frac{\operatorname{cov}(M, O)}{\sqrt{\operatorname{cov}(M) \operatorname{cov}(O)}},
\end{aligned}
$$

where $B$, RMSE, SI, and $\rho$ are bias, root-mean-square error, scatter index, and Pearson's correlation coefficient, respectively. The quantities, $M, O$, and $N$ represent model, observation, and the number of points, respectively.

Figures 3 and 4 show each of these quantities, before and after the calibration relations of Table 1 are applied. After performing nonlinear calibrations, all observed statistical parameters improve. The most striking change occurred for $E R S$-2 where RMSE decreased from 1.7182 to $1.4166 \mathrm{~m} \mathrm{~s}^{-1}$ (decrease of approximately 18\%) and the bias reduces in magnitude from $-0.378 \mathrm{~m} \mathrm{~s}^{-1}$ to approximately zero after the 

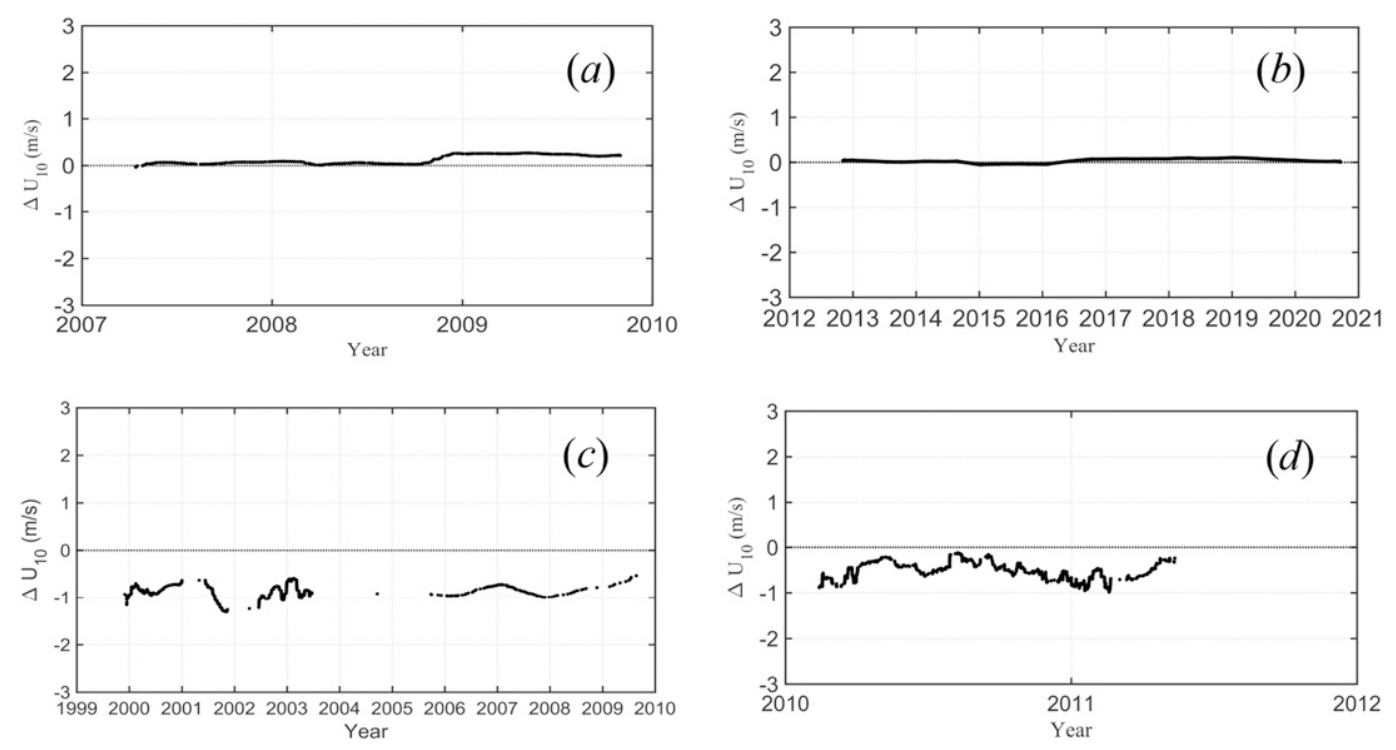

FIG. 7. As in Fig. 5, but for scatterometer-scatterometer difference as a function of time. (a) MetOp-A QuikSCAT, (b) MetOp-A - MetOp-B, (c) QuikSCAT - ERS-2, and (d) OceanSat-2 - ERS-2.

calibration is applied. In all cases, the bias is zero to three decimal places once the calibration is applied. In addition, the Q-Q plots of Fig. 4 show good agreement between scatterometer and measured data over the full range of wind speed values.

\section{Cross validation between scatterometers}

Further observation and validation of the suitability of the polynomial calibration at low to moderate wind speeds $(0$ $30 \mathrm{~m} \mathrm{~s}^{-1}$ ) was carried out by performing cross validation between calibrated scatterometers. As presented in Fig. 1, seven possible cross validations can be performed. However, for simplicity, only four are presentation here, namely, $\mathrm{Met} O \mathrm{p}-\mathrm{A}-\mathrm{MetOp}-\mathrm{B}, \mathrm{MetOp}$ A-QuikSCAT, QuikSCAT-ERS-2, and OceanSat-2-ERS-2. As noted above, QuikSCAT was not recalibrated as part of this process, as Tamizi and Young (2020) found that there was no measurable underestimation of wind speeds from this instrument in tropical cyclone conditions. For QuikSCAT, the linear calibration of Ribal and Young (2020b) was applied.

The same matchup criteria as applied by Ribal and Young (2020b) were used for the satellite-satellite validations, in which the spatial and temporal separation are a maximum of $50 \mathrm{~km}$ and $30 \mathrm{~min}$, respectively. The one exception was for $M e t O p$ - $A$ and $M e t O p-B$, where a time mismatch of 60 min was used, as these instruments are in a tandem orbit configuration with a time delay of $49 \mathrm{~min}$. In addition, since the number of matchups between $\mathrm{Met} O p-A$ and $M e t O p-B$ is very large, only eighteen $15^{\circ} \times 15^{\circ}$ regions were selected, as defined by Ribal and Young (2020b) and shown in Fig. 2. After applying the matchup criteria and limiting the geographic distribution of the matchup regions, MetOp-A and MetOp-B still yield 2095140 matchups, as shown in Fig. 5b. In such a validation, conventional linear regression is not appropriate, as neither instrument can be considered as "ground truth." To overcome this limitation, RMA regression has been applied (Young et al.
2017). The main advantage of this method compared to conventional linear regression is that RMA can accommodate situations where there are potential errors in both quantities in the regression. In addition, this method can exclude data which are considered as outliers (Ribal and Young 2020b).

Figure 5 shows scatterplots between the selected scatterometers. The blue dots show the matchup data, and the black dots represent points flagged as outliers by the RMA regression. The thick solid line represents the RMA regression result, while the dashed diagonal line represents the 1:1 relationship. Shaded contours showing the density of observations are also shown. As can be seen from Fig. 5a (MetOp- $A$ and QuikSCAT) and Fig. 5b (MetOp-A and $M e t O p-B)$, the RMA regression is in good agreement with the 1:1 relationship. In addition, the values of the statistical parameters (bias, correlation coefficient, and scatter index) for the cases $M e t O p$ - $A$-QuikSCAT and $M e t O p-A-M e t O p-B$ are slightly better than the results of Ribal and Young (2020b), who used a linear calibration relationship based only on buoys. Although the comparisons between QuikSCAT-ERS-2 (Fig. 5c) and OceanSat-2-ERS-2 (Fig. 5d) are not as good as the other two cases, they are still in a relatively good agreement. The total number of matchups between QuikSCAT and ERS-2 is only 14510 and all of these points are in the Southern Hemisphere, e.g., between $50^{\circ}$ and $90^{\circ} \mathrm{S}$. Young and Donelan (2018) have shown that satellite remote sensing measurements of wind speed are impacted by boundary layer stability. Therefore, when validations such as those shown in Fig. 5 occur for latitudes significantly different from those where the calibration has occurred, small differences can result. We believe this is the most likely reason why the validation results in Fig. 5 show small differences from the $1: 1$ line.

$\mathrm{Q}-\mathrm{Q}$ plots between respective scatterometers are also shown in Fig. 6. It is again clear that the $\operatorname{Met} O p-A$ and QuikSCAT (Fig. 6a) and $M e t O p$ - $A$ and $M e t O p-B$ (Fig. 6b) are in good agreement, as seen in the scatterplots (Fig. 5). The 
other two cases show that ERS-2 slightly overestimates compared to both QuikSCAT and OceanSat-2 at high wind speeds. Moreover, the cross validation between $\operatorname{Met} O p-A$ and $E R S-2$ (not shown here) show a similar pattern in which $E R S-2$ is slightly higher. This is also consistent with the results of Ribal and Young (2020b), who used linear calibrations for both scatterometers.

To observe the temporal stability of the calibrated scatterometer data, the difference between scatterometers as a function of time has also been evaluated as presented in Fig. 7. As can be seen from the figures, the present results are very consistent with the results of Ribal and Young (2020b) where the measurements of C-band satellites are slightly higher than Ku-band scatterometers. As described by Young and Donelan (2018), it is believed that this is a result of the differing impact of boundary layer stability on the different scatterometers. The fact that QuikSCAT-ERS-2 matchups are limited to high latitudes in the Southern Hemisphere is noted above and the difference in wind speed is clear in Fig. 7c. Although the matchup locations between OceanSat-2 and ERS-2 (Fig. 7d) are more evenly distributed around the globe, the matchups in the Southern Hemisphere still dominant in terms of numbers as well as the deviation from 0 for the wind speed differences as a function of time. These results are consistent with the results of Young and Donelan (2018) for altimeters and radiometers.

\section{Conclusions}

The present study has recalibrated four different scatterometers under extreme wind conditions, up to $45 \mathrm{~m} \mathrm{~s}^{-1}$. To develop relationships valid over the full range of wind speeds from 0 to $45 \mathrm{~m} \mathrm{~s}^{-1}$, a combination of NDBC buoy data and SFMR hurricane data wind speed which are greater than $15 \mathrm{~m} \mathrm{~s}^{-1}$ have been used. The data clearly show that, at high wind speeds, the relationships between "ground truth" and scatterometer wind speeds is nonlinear. Polynomial relationships have been used as calibration functions, valid over the full range of wind speeds. $\mathrm{Met} O \mathrm{P}-\mathrm{A}$ and $\mathrm{Met} O \mathrm{P}-\mathrm{B}$ are best fitted by third-order polynomial calibration relations, while ERS-2 and OceanSat-2 can be represented by quadratic calibration relations.

The evaluation of statistical parameters shows that the statistical parameters representing the performance of the scatterometers (bias, RMSE) are improved by this nonlinear approach, compared to the results of Ribal and Young (2020b) in which linear corrections based solely on NDBC buoy data were developed. In addition, the present results extend the upper wind speed limit for the validity of scatterometer data from approximately 23 to $45 \mathrm{~m} \mathrm{~s}^{-1}$. Cross validation between calibrated scatterometers has also been performed. The results show good agreement between scatterometers as measured by bias and RMSE. In addition, the difference between scatterometers as a function of time shows that the instruments are stable over their respective measurement periods, without obvious drift or changes in calibration.

The present results indicate that scatterometers, calibrated as proposed in this paper, can be used at extreme wind speeds, such as encountered in tropical cyclone (hurricane) conditions.
Acknowledgments. The authors acknowledge the Integrated Marine Observing System (IMOS) for ongoing support in development of the database. This study was supported by funding from a Melbourne-Indonesia Research Partnership Program 2020 grant.

\section{REFERENCES}

Alsabah, R., A. Al-Sabbagh, and J. Zec, 2018: RapidScat backscatter measurement validation. J. Appl. Remote Sens., 12, 034005, https://doi.org/10.1117/1.JRS.12.034005.

Alves, J. H. G. M., and I. R. Young, 2003: On estimating extreme wave heights using combined Geosat, TOPEX/Poseidon and ERS-1 altimeter data. Appl. Ocean Res., 25, 167-186, https:// doi.org/10.1016/j.apor.2004.01.002.

Bender, L. C., III, N. L. Guinasso Jr., J. N. Walpert, and S. D. Howden, 2010: A comparison of methods for determining significant wave heights-Applied to a 3-m discus buoy during Hurricane Katrina. J. Atmos. Oceanic Technol., 27, 1012-1028, https://doi.org/10.1175/2010JTECHO724.1.

Bentamy, A., D. Croize-Fillon, and C. Perigaud, 2008: Characterization of ASCAT measurements based on buoy and QuikSCAT wind vector observations. Ocean Sci., 4, 265-274, https://doi.org/10.5194/ os-4-265-2008.

Chou, K.-H., C.-C. Wu, and S.-Z. Lin, 2013: Assessment of the ASCAT wind error characteristics by global dropwindsonde observations. J. Geophys. Res. Atmos., 118, 9011-9021, https:// doi.org/10.1002/jgrd.50724.

Collins, C., H. Potter, B. Lund, H. Tamura, and H. C. Graber, 2018: Directional wave spectra observed during intense tropical cyclones. J. Geophys. Res. Oceans, 123, 773-793, https:// doi.org/10.1002/2017JC012943.

DiNapoli, S. M., M. A. Bourassa, and M. D. Powell, 2012: Uncertainty and intercalibration analysis of $\mathrm{H}^{*}$ Wind. J. Atmos. Oceanic Technol., 29, 822-833, https://doi.org/10.1175/JTECHD-11-00165.1.

Evans, D., C. Conrad, and F. Paul, 2003: Handbook of automated data quality control checks and procedures of the National Data Buoy Center. NOAA/National Data Buoy Center Doc., $44 \mathrm{pp}$.

Hersbach, H., A. Stoffelen, and S. de Haan, 2007: An improved C-band scatterometer ocean geophysical model function: CMOD5. J. Geophys. Res., 112, C03006, https://doi.org/ 10.1029/2006JC003743.

Holland, G. J., 1980: An analytic model of the wind and pressure profiles in hurricanes. Mon. Wea. Rev., 108, 1212-1218, https://doi.org/ 10.1175/1520-0493(1980)108<1212:AAMOTW>2.0.CO;2.

_ J. I. Belanger, and A. Fritz, 2010: A revised model for radial profiles of hurricane winds. Mon. Wea. Rev., 138, 4393-4401, https://doi.org/10.1175/2010MWR3317.1.

Holland, P. W., and R. E. Welsch, 1977: Robust regression using iteratively reweighted least-squares. Commun. Stat. Theory Methods, 6, 813-827, https://doi.org/10.1080/03610927708827533.

Hu, K., Q. Chen, and S. K. Kimball, 2012: Consistency in hurricane surface wind forecasting: An improved parametric model. Nat. Hazards, 61, 1029-1050, https://doi.org/10.1007/s11069-0119960-z.

Huber, P. J., 2005: Robust Statistics. Vol. 579. Wiley, 320 pp.

Jensen, R., V. Swail, R. Bouchard, R. Riley, T. Hesser, M. Blaseckie, and C. MacIsaac, 2015: Field Laboratory for Ocean Sea State Investigation and Experimentation: FLOSSIE: Intrameasurement evaluation. 14th Int. Workshop on Wave Hindcasting and Forecasting/Fifth Coastal Hazard Symp., 
Southampton, United Kingdom, U.K. National Oceanography Centre, https://noc-events.co.uk/sites/conference.noc.ac.uk/ files/documents/S1E1.pdf.

Klotz, B. W., and H. Jiang, 2016: Global composites of surface wind speeds in tropical cyclones based on a 12 year scatterometer database. Geophys. Res. Lett., 43, $10480-10488$, https:// doi.org/10.1002/2016GL071066.

_ and - 2017: Examination of surface wind asymmetries in tropical cyclones. Part I: General structure and wind shear impacts. Mon. Wea. Rev., 145, 3989-4009, https://doi.org/ 10.1175/MWR-D-17-0019.1.

Knapp, K. R., H. J. Diamond, J. P. Kossin, M. C. Kruk, and C. J. Schreck, 2018: International Best Track Archive for Climate Stewardship (IBTrACS) project, version 4. NOAA/National Centers for Environmental Information, accessed 10 October 2019, https://doi.org/10.25921/82ty-9e16.

Large, W. G., J. Morzel, and G. B. Crawford, 1995: Accounting for surface wave distortion of the marine wind profile in low-level ocean storms wind measurements. J. Phys. Oceanogr., 25, 2959-2971, https://doi.org/10.1175/1520-0485(1995)025<2959: AFSWDO $>2.0 . \mathrm{CO} ; 2$.

Leys, C., C. Ley, O. Klein, P. Bernard, and L. Licata, 2013: Detecting outliers: Do not use standard deviation around the mean, use absolute deviation around the median. J. Exp. Soc. Psychol., 49, 764-766, https://doi.org/10.1016/j.jesp.2013.03.013.

Madsen, N. M., and D. G. Long, 2016: Calibration and validation of the RapidScat scatterometer using tropical rainforests. IEEE Trans. Geosci. Remote Sens., 54, 2846-2854, https://doi.org/ 10.1109/TGRS.2015.2506463.

Miller, J., 1991: Reaction time analysis with outlier exclusion: Bias varies with sample size. Quart. J. Exp. Psychol., 43A, 907-912, https://doi.org/10.1080/14640749108400962.

Pensieri, S., R. Bozzano, and M. E. Schiano, 2010: Comparison between QuikSCAT and buoy wind data in the Ligurian Sea. J. Mar. Syst., 81, 286-296, https://doi.org/10.1016/ j.jmarsys.2010.01.004.

Powell, M. D., S. H. Houston, L. R. Amat, and N. MorisseauLeroy, 1998: The HRD real-time hurricane wind analysis system. J. Wind Eng. Ind. Aerodyn., 77-78, 53-64, https:// doi.org/10.1016/S0167-6105(98)00131-7.

Ribal, A., and I. R. Young, 2019: 33 years of globally calibrated wave height and wind speed data based on altimeter observations. Sci. Data, 6, 77, https://doi.org/10.1038/s41597-019-0083-9.

$\longrightarrow$, and - 2020a: Global calibration and error estimation of altimeter, scatterometer, and radiometer wind speed using triple collocation. Remote Sens., 12, 1997, https://doi.org/ 10.3390/rs12121997.

$\longrightarrow$, and - 2020b: Calibration and cross validation of global ocean wind speed based on scatterometer observation. J. Atmos. Oceanic Technol., 37, 279-297, https://doi.org/ 10.1175/JTECH-D-19-0119.1.

Rousseeuw, P. J., and C. Croux, 1993: Alternatives to the median absolute deviation. J. Amer. Stat. Assoc., 88, 1273-1283, https://doi.org/10.1080/01621459.1993.10476408.

Satheesan, K., A. Sarkar, A. Parekh, M. R. R. Kumar, and Y. Kuroda, 2007: Comparison of wind data from QuikSCAT and buoys in the Indian Ocean. Int. J. Remote Sens., 28, 23752382, https://doi.org/10.1080/01431160701236803.

Tamizi, A., and I. R. Young, 2020: The spatial distribution of ocean waves in tropical cyclones. J. Phys. Oceanogr., 50, 2123-2139, https://doi.org/10.1175/JPO-D-20-0020.1.

,,-- A. Ribal, and J.-H. Alves, 2020: Global scatterometer observations of the structure of tropical cyclone wind fields.
Mon. Wea. Rev., 148, 4673-4692, https://doi.org/10.1175/ MWR-D-20-0196.1.

Taylor, P. K., and M. J. Yelland, 2001: Comments on "On the effect of ocean waves on the kinetic energy balance and consequences for the inertial dissipation technique." J. Phys. Oceanogr., 31, 2532-2536, https://doi.org/10.1175/1520-0485(2001)031<2532: COOTEO $>2.0 . \mathrm{CO} ; 2$.

Ueno, M., and K. Bessho, 2011: A statistical analysis of near-core surface wind asymmetries in typhoons obtained from QuikSCAT data. J. Meteor. Soc. Japan, 89, 225-241, https://doi.org/10.2151/ jmsj.2011-304.

Uhlhorn, E. W., and P. G. Black, 2003: Verification of remotely sensed sea surface winds in hurricanes. J. Atmos. Oceanic Technol., 20, 99-116, https://doi.org/10.1175/1520-0426(2003) 020<0099:VORSSS $>2.0$.CO;2.

,-- J. L. Franklin, M. Goodberlet, J. Carswell, and A. S. Goldstein, 2007: Hurricane surface wind measurements from an operational stepped frequency microwave radiometer. Mon. Wea. Rev., 135, 3070-3085, https://doi.org/10.1175/ MWR3454.1.

— , B. W. Klotz, T. Vukicevic, P. D. Reasor, and R. F. Rogers, 2014: Observed hurricane wind speed asymmetries and relationships to motion and environmental shear. Mon. Wea. Rev., 142, 1290-1311, https://doi.org/10.1175/MWR-D-13-00249.1.

Verhoef, A., M. Portabella, and A. Stoffelen, 2012: High-resolution ASCAT scatterometer winds near the coast. IEEE Trans. Geosci. Remote Sens., 50, 2481-2487, https://doi.org/10.1109/ TGRS.2011.2175001.

Verspeek, J., A. Stoffelen, M. Portabella, A. Verhoef, and J. Vogelzang, 2008: ASCAT scatterometer ocean calibration. Int. Geoscience and Remote Sensing Symp., Boston, MA, IEEE, V248-V251, https://doi.org/10.1109/IGARSS.2008.4780074.

Vinoth, J., and I. R. Young, 2011: Global estimates of extreme wind speed and wave height. J. Climate, 24, 1647-1665, https:// doi.org/10.1175/2010JCLI3680.1.

Willoughby, H., R. Darling, and M. Rahn, 2006: Parametric representation of the primary hurricane vortex. Part II: A new family of sectionally continuous profiles. Mon. Wea. Rev., 134, 1102-1120, https://doi.org/10.1175/MWR3106.1.

Xie, L., S. Bao, L. J. Pietrafesa, K. Foley, and M. Fuentes, 2006: A realtime hurricane surface wind forecasting model: Formulation and verification. Mon. Wea. Rev., 134, 1355-1370, https://doi.org/ 10.1175/MWR3126.1.

Young, I. R., 1998: Observations of the spectra of hurricane generated waves. Ocean Eng., 25, 261-276, https://doi.org/10.1016/ S0029-8018(97)00011-5.

_ 2006: Directional spectra of hurricane wind waves. J. Geophys. Res., 111, C08020, https://doi.org/10.1029/2006JC003540.

- 2017: A review of parametric descriptions of tropical cyclone wind-wave generation. Atmosphere, 8, 194, https://doi.org/ 10.3390/atmos8100194.

_ spatial distribution of tropical cyclone wind-waves as observed by altimeter. Ocean Eng., 70, 14-24, https://doi.org/ 10.1016/j.oceaneng.2013.05.015.

, and M. A. Donelan, 2018: On the determination of global ocean wind and wave climate from satellite observations. Remote Sens. Environ., 215, 228-241, https://doi.org/10.1016/j.rse.2018.06.006.

_ , and A. Ribal, 2019: Multiplatform evaluation of global trends in wind speed and wave height. Science, 364, 548-552, https:// doi.org/10.1126/science.aav9527.

_- E. Sanina, and A. V. Babanin, 2017: Calibration and cross validation of a global wind and wave database of altimeter, 
radiometer, and scatterometer measurements. J. Atmos. Oceanic Technol., 34, 1285-1306, https://doi.org/10.1175/JTECH-D-16-0145.1. E. Kirezci, and A. Ribal, 2020: The global wind resource observed by scatterometer. Remote Sens., 12, 2920, https:// doi.org/10.3390/rs12182920.

Zeng, L., and R. A. Brown, 1998: Scatterometer observations at high wind speeds. J. Appl. Meteor., 37, 1412-1420, https://doi.org/ 10.1175/1520-0450(1998)037<1412:SOAHWS > 2.0.CO;2.

Zhang, J. A., and E. W. Uhlhorn, 2012: Hurricane sea surface inflow angle and an observation-based parametric model. Mon.
Wea. Rev., 140, 3587-3605, https://doi.org/10.1175/MWR-D11-00339.1.

Zieger, S., J. Vinoth, and I. R. Young, 2009: Joint calibration of multiplatform altimeter measurements of wind speed and wave height over the past 20 years. J. Atmos. Oceanic Technol., 26, 2549-2564, https://doi.org/10.1175/2009JTECHA1303.1.

, A. V. Babanin, W. Erick Rogers, and I. R. Young, 2015: Observation-based source terms in the third-generation wave model WAVEWATCH. Ocean Modell., 96, 2-25, https:// doi.org/10.1016/j.ocemod.2015.07.014. 